\title{
G Protein Signaling Mediates Developmental Processes and Pathogenesis of Alternaria alternata
}

\author{
Daisuke Yamagishi, Hiroshi Otani, and Motoichiro Kodama \\ Laboratory of Plant Pathology, Faculty of Agriculture, Tottori University, 4-101 Koyama-Minami, Tottori 680-8553, Japan \\ Submitted 26 January 2006. Accepted 4 June 2006.
}

\begin{abstract}
A G protein $\alpha$ subunit gene (AGA1) has been cloned and characterized from a toxigenic and necrotrophic Alternaria alternata pathogen. Targeted disruption of $A G A 1$ in the apple pathotype of $A$. alternata gave rise to mutants that differed in colony and conidial morphology as well as sporulation. The conidia of wild type and $\triangle A G A 1$ mutants showed equal germination on cellulose membranes. However, wild-type germ tubes formed readily from different points around the conidia, grew randomly, and were often branched, whereas those of the mutants formed only at one or both ends of the conidia and tended to grow in straight paths. Targeted disruption of $A G A 1$ also resulted in reduction of pathogenicity on apple leaves, although the mutant produced host-specific AM-toxin, a fungal secondary metabolite associated with pathogenicity of the pathogen, at levels similar to the wild-type strain. Measurement of the intracellular cAMP levels of the mutant revealed that it was consistently higher than that of the wild type, indicating that $A G A 1$ negatively regulates cAMP levels similar to mammalian Goi systems. These results indicate that the signal transduction pathway represented by $A G A 1$ appears to be involved in developmental pathways leading to sporulation and pathogenesis of $A$. alternata.
\end{abstract}

Additional keywords: Alternaria blotch of apple, AMT, general pathogenesis, host-specific toxin.

Alternaria alternata (Fries) Keissler is a ubiquitous fungus that can be found on many kinds of plants, animals, and other substrata, including foodstuffs and soil. Many strains of this fungus are known to be saprophytic, but some are notorious for causing severe diseases on various plants. Among such plant pathogenic A. alternata, at least seven pathogens are known to produce host-specific toxins (HST) (Kohmoto and Otani 1991; Otani et al. 1995; Thomma 2003). HST produced by plant-pathogenic fungi are generally low-molecular weight secondary metabolites and are critical determinants of hostspecific pathogenicity or virulence in several plant-pathogen interactions (Kohmoto and Otani 1991; Markham and Hille 2001; Thomma 2003; Walton 1996; Wolpert et al. 2002). The mechanisms of host-selective pathogenesis through the participation of HST are well understood (Kohmoto and Otani 1991; Markham and Hille 2001; Wolpert et al. 2002).

Corresponding author: M. Kodama; E-mail: mk@muses.tottori-u.ac.jp

Nucleotide sequence data for $A G A 1$ is available in the DDBJ, EMBL, plus the GenBank nucleotide sequence databases under accession number AB239917.
The apple pathotype of A. alternata causes Alternaria blotch of apple on a narrow range of susceptible apple cultivars, depending on the production of a host-specific AM-toxin (Kohmoto et al. 1974). This disease is one of the most serious diseases of worldwide apple cultivation (Sawamura 1996). AM-toxin consists of a four-membered cyclic depsipeptide (Nishimura and Kohmoto 1983; Okuno et al. 1974), and we have previously cloned the $A M T$ gene encoding a cyclic peptide synthetase, which has a crucial role in AM-toxin biosynthesis (Johnson et al. 2000). Disruption of $A M T$ resulted in complete loss of toxin production and pathogenicity, indicating that the gene is a major pathogenicity gene of the pathogen (Johnson et al. 2000).

In addition to $A M T$, genes for biosynthesis of several HST produced by $A$. alternata pathogens have been isolated (Hatta et al. 2002; Tanaka et al. 1999). In all cases, knock-out of the genes involved resulted in a nonpathogenic phenotype (Hatta et al. 2002; Tanaka et al. 1999). The genes for HST biosynthesis are therefore clearly involved in fungal host specificity, but additional genes and factors have also been shown to be required for general pathogenesis of phytopathogenic fungi (Idnurm and Howlett 2001). To date however, with the exception of cell wall-degrading enzymes (Isshiki et al. 2001; Yao and Koller 1995), general pathogenicity genes or factors for establishment of basic compatibility have not been elucidated for HST-producing and necrotrophic Alternaria pathogens.

The ability to sense and respond to external stimuli through signal transduction during infection has been shown to be an essential step in general pathogenicity (Bölker 1998; Idnurm and Howlett 2001; Lengeler et al. 2000). Heterotrimeric GTPbinding proteins ( $\mathrm{G}$ proteins) are involved in regulating a variety of cellular functions in eukaryotes (Neer et al. 1995; Simon et al. 1991). $G$ protein complexes are composed of $\alpha, \beta$, and $\gamma$ subunits and mediate the transduction of numerous signals that are perceived by transmembrane receptors to intracellular effectors, such as adenylate cyclase, phospholipases, and ion channels (Neer 1995; Simon et al. 1991). In the inactive form, the $\alpha$ subunit binds GDP and the $\beta \gamma$ heterodimer with high affinity. Activation by extracellular signals results in the exchange of GDP for GTP and disassociation of the three subunits as GTP-G $\alpha$ and $-G \beta \gamma$, both of which alter the activity of a diverse set of intracellular effector molecules. Hydrolysis of GTP to GDP by an intrinsic GTPase results in signal termination and reassociation of $G \alpha$ with $G \beta \gamma$ (Neer et al. 1995).

In fungi, multiple genes for $\mathrm{G}$ proteins, especially for $\mathrm{G} \alpha$ proteins, have been identified and demonstrated to mediate complex biological processes (Bölker 1998; Lengeler et al. 2000). These include fadA from Aspergillus nidulans (Yu et al. 1996), cpgl from Cryphonectria parasitica (Gao and Nuss 1996), magA, magB, and magC from Magnaporthe grisea (Liu and Dean 1997), gnal and gna2 from Neurospora crassa 
(Turner and Borkovich 1993), gpal to gna4 from Ustilago maydis (Regenfelder et al. 1997), CGAl from Cochliobolus heterostrophus (Horwitz et al. 1999), ctgl from Colletotrichum trifolii (Truesdell et al. 2000), bcgl and bcg2 from Botrytis cinerea (Gronover et al. 2001), fgal from Fusarium oxysporum (Jain et al. 2002), and Gnal from Stagonospora nodorum (Solomon et al. 2004). Functional analysis of the $\mathrm{G} \alpha$ genes through targeted gene disruption has revealed that the genes control a number of complex and important fungal processes, including vegetative growth, sporulation, mating, development of infection structures, and pathogenicity and virulence. For example, disruption of $c p g-1$ from the chestnut blight fungus Cryphonectria parasitica resulted in defects of reproduction and virulence (Gao and Nuss 1996). In the rice blast fungus $M$. grisea, disruption of $m a g B$ induced extensive phenotypic changes: growth, conidiation, appressorium formation, mating, and pathogenicity (Liu and Dean 1997). CGAl from Cochliobolus heterostrophus is required for mating and development of appressoria but not for fungal virulence (Horwitz et al. 1999). On the other hand, ctgl from Colletotrichum trifolii is involved in spore germination (Truesdell et al. 2000). Disruption of $U$. maydis gpa3, B. cinerea bcgl, and $F$. oxysporum fgal also resulted in mutants defective in virulence (Gronover et al. 2001). Furthermore, a fungal $\mathrm{G} \alpha$ subunit has been shown to mediate the production of toxic secondary metabolites (Hicks et al. 1997; Tag et al. 2000; Yu and Keller 2005). Production of the mycotoxins sterigmatocystin and aflatoxin in Aspergillus

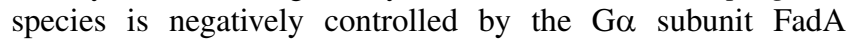
(Hicks et al. 1997). In contrast, the dominant activating fadA allele $\mathrm{fadA}^{\mathrm{G} 42 \mathrm{R}}$ increases penicillin production by $A$. nidulans and also stimulates mycotoxin trichothecene production by $F$. sporotrichioides (Tag et al. 2000). It is, therefore, possible that $\mathrm{G} \alpha$ genes in other plant pathogenic fungi might control production of toxic secondary metabolites, such as HST, which have critical roles in fungal pathogenesis.

To investigate possible signal transduction pathways involved in general pathogenesis of A. alternata, we have cloned and characterized a $\mathrm{G} \alpha$ gene from the apple pathotype of $A$. alternata. In addition, we determined whether this gene, designated $A G A 1$, controls the production of HST secondary metabolites, which determine host-specific pathogenicity or virulence of the pathogen.

\section{RESULTS}

\section{Cloning and characterization of $A G A 1$.}

Polymerase chain reaction (PCR) products of the expected size $(200 \mathrm{bp})$ were obtained from the apple pathotype of $\mathrm{A}$. alternata (M-71), with degenerate oligonucleotide primers aga-F and aga-R. These products were subcloned into pBlucecript KS via introduced $X b a \mathrm{I}$ sites and were sequenced with T3 and T7 universal primers. The deduced amino-acid sequence of the 200bp product showed high similarity with fungal $\mathrm{G} \alpha$ proteins in the sequence databases. This PCR product was used as a hybridization probe to screen an A. alternata apple pathotype genomic library. Positive clones were purified two times and were converted to pBKCMV phagemids for sequencing. Sequence analysis of all three positive clones revealed one predicted open reading frame (designated $A G A 1$ ) of $1,528 \mathrm{bp}$ (406 amino acids) interrupted by three putative introns BLAST searches (Altschul et al. 1997) showed that $A G A 1$ had a high degree of identity with CGAl from Cochliobolus heterostrophus (98\%) (Horwitz et al. 1999), magB from M. grisea (94\%) (Liu and Dean 1997), CPG1 from Cryphonectria parasitica (95\%) (Gao and Nuss 1996), ctgl from Colletotrichum trifolii (94\%) (Truesdell et al. 2000), and Gna-1 from N. crassa (94\%) (Turner and Borkovich 1993). AGA1 is also 54\% identical to mammalian Gai subunit.
Sequence analysis of the AGA1 protein showed that it contains conserved domains for N-terminal myristoylation (MGXXXS; Buss et al. 1987) and the C-terminal ADP-ribosylation by pertussis toxin (CXXX; Simon et al. 1991; West et al. 1985), characteristics of mammalian Goi family members.

\section{Disruption of $A G A 1$ by homologous recombination.}

The $A G A 1$ disruption vector was constructed by ligating three fragments, an $A G A 1$ genomic sequence corresponding to -189 to 626 , a hygromycin resistance cassette composed of the
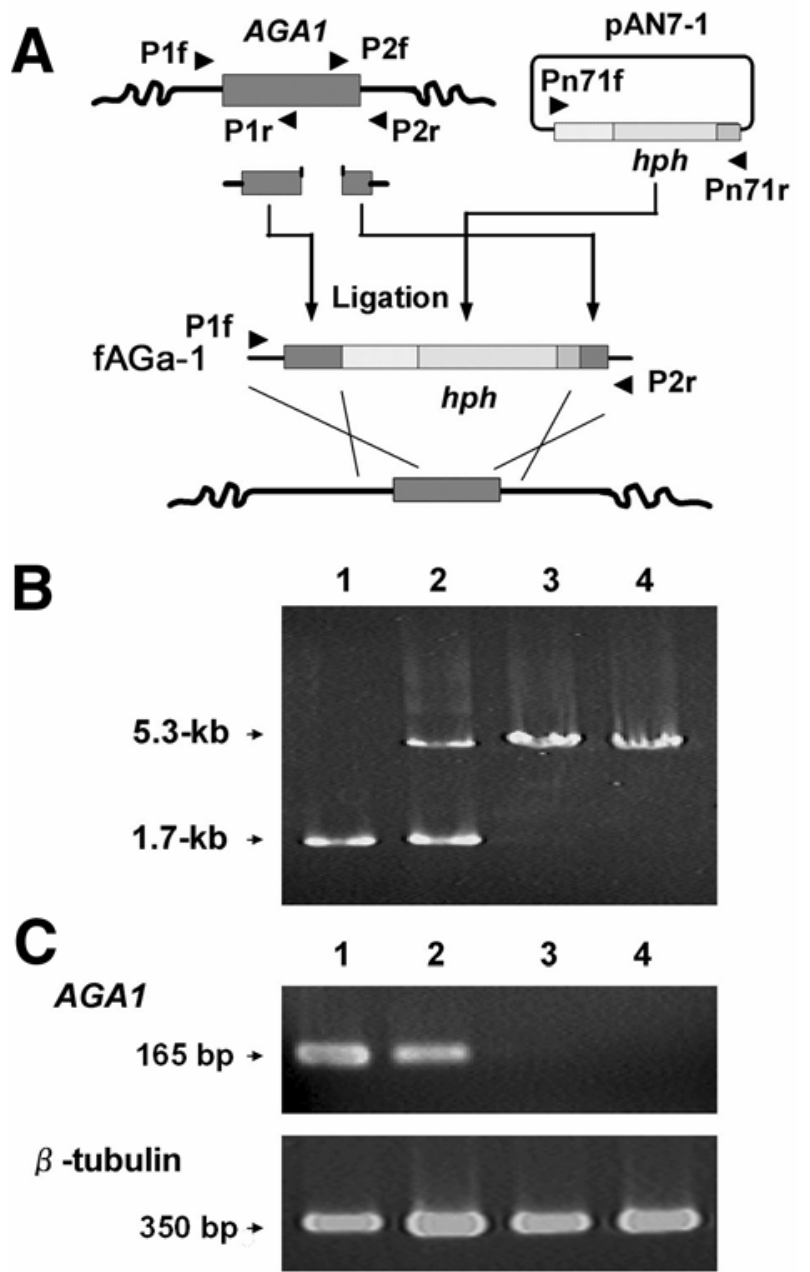

Fig. 1. AGA1-targeted disruption in the apple pathotype of Alternaria alternata. A, Construction of the targeting vector fAGa-1and targeted disruption of the $A G A 1$ locus. To make fAGa-1, two polymerase chain reaction (PCR) fragments internal to $A G A 1$ were amplified from genomic DNA of IFO8984 by primers P1f and P1r and P2f and P2r combinations. The P1r and P2f primers have HindIII and XbaI sites at the $5^{\prime}$ ends, respectively. The $h p h$ (hygromycin B-resistant gene) cassette was amplified from pAN7-1 (Punt et al. 1987) by primers Pn71f and Pn71r, which have HindIII and $\mathrm{XbaI}$ sites at the $5^{\prime}$ ends, respectively. The resulting three fragments were ligated and amplified by P1f and P2r to get fAGa-1. Diagonal boxes indicate the coding sequences of $A G A 1$. A homologous crossover between cloned and genomic DNA is shown. B, PCR analysis of wild type and transformants with primers (P1f and P2r) designed to detect homologous recombination events. 1, wild-type strain IFO8984; 2, ectopic transformant I-15; 3, disruptant Igd-34; and 4, disruptant Igd-36. The 1.7-kb band representing part of the wild-type copy of $A G A 1$ was replaced by a $5.3-\mathrm{kb}$ band in the disruption mutants Igd-34 and Igd-36. PCR amplification of both the 1.7- and 5.3-kb bands in I-15 represents an ectopic integration event. C, Detection of AGAl transcript in wild type and transformants. Total RNA extracted from the same isolates used in B was used as templates for reverse transcription-PCR. Primers aga-1F and aga-1R detect an internal fragment (165 bp) of $A G A 1$. Primers specific for $\beta$-tubulin were used as a positive control. 
Escherichia coli hph gene flanked by the A. nidulans GPD promoter and terminator, and another $A G A 1$ genomic sequence corresponding to 1,067 to 1,551 (AB239917). After ligation a linear construct was amplified by PCR using a set of primers at both ends of the fragment to generate the $A G A l$ replacement construct fAGa-1 (Fig. 1A). The fAGa-1 PCR product was used directly in transformations.
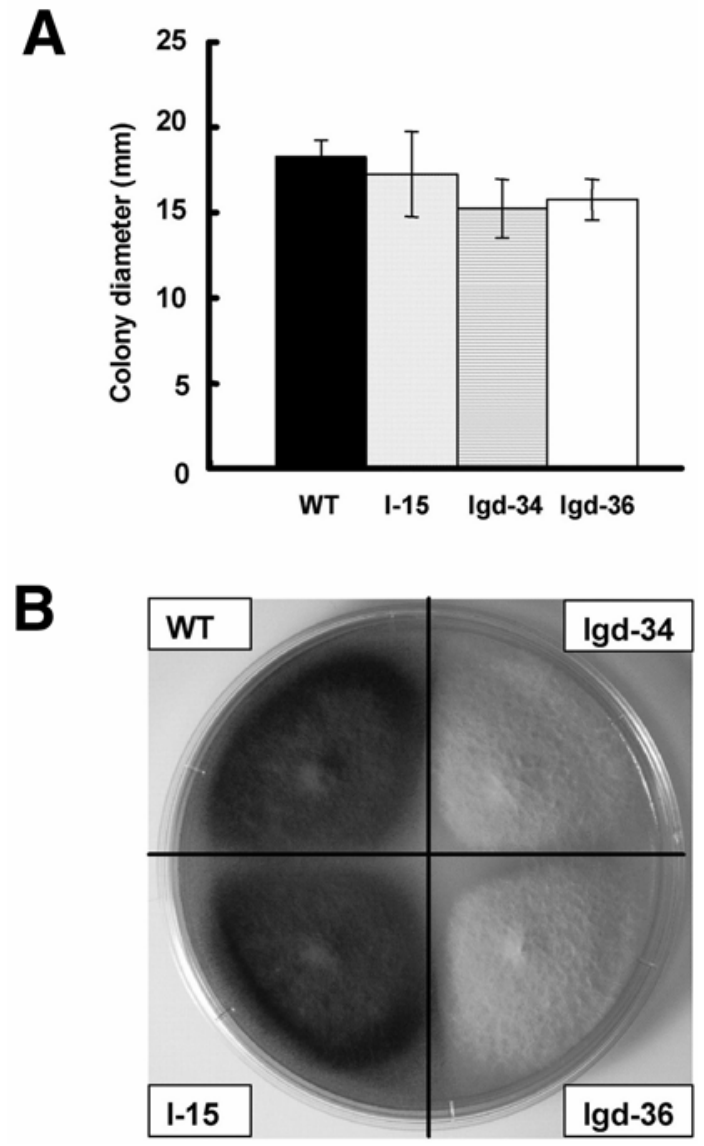

Fig. 2. Vegetative growth and colony morphology of AGA1-targeted mutants. A, Colony diameter of three-day cultures. Wild-type strain IFO8984, ectopic transformant I-15, and AGAl-targeted mutants Igd-34 and Igd-36 were grown on V-8 juice agar (V8A) at $25^{\circ} \mathrm{C}$. Data represent means \pm standard deviation of three replications. B, Colony morphology of the wild-type strain, ectopic transformant, and AGAl-targeted mutants grown on V8A at $25^{\circ} \mathrm{C}$ for five days.
Transformation of the apple pathotype of A. alternata IFO8984 protoplasts with fAGa-1 (Fig. 1A) yielded hygromycin B-resistant transformants at a high frequency (60 per $10^{7}$ protoplasts per $5 \mu \mathrm{g}$ of DNA). Genomic DNA was isolated from the transformants and was screened by PCR with primers (P1f and P2r) to detect replacement events (Fig. 1B). The 1.7$\mathrm{kb}$ band representing part of the wild-type copy of $A G A l$ was replaced by a $5.3-\mathrm{kb}$ band containing the $h p h$ cassette in the disruption mutants Igd-34 and Igd-36 (Fig. 1B). PCR amplification of both the 1.7- and 5.3-kb bands in I-15 represents an ectopic integration event of the disruption construct in the wild-type genome (Fig. 1B). No ectopic integration event in the disruption mutants had been confirmed by Southern blotting with the $A G A 1$ probe (data not shown).

Reverse transcription (RT)-PCR was performed on total RNA of the wild type and transformants to confirm absence of $A G A l$ transcript in the disruption mutants. With $A G A 1$-specific primers (P1f and P2r), the wild type and the ectopic transformant I-15 gave a 165-bp product (Fig. 1C), while transformants Igd-34 and Igd-36 showed no band, indicating $A G A 1$ is completely disrupted and intact transcript is absent (Fig. 1C).

\section{Phenotypic characterization}

of $A G A 1$ disruptants and its $A G A 1$-complemented strains.

The two disruption mutants had altered colony morphology and growth rate as compared with the wild-type colony morphology (Fig. 2). Vegetative growth of the disruptants Igd-34 and Igd-36, measured as colony diameter on V-8 juice agar (V8A) was slightly reduced by $15 \%$ as compared with that of the wild-type strain (Fig. 2A). In addition, disruption of $A G A 1$ induced vigorous growth of aerial hypha on V8A (Fig. 2B). Sporulation of the disruption mutants also dramatically decreased during culture on V8A under fluorescent light or in the dark (Table 1), whereas the wild-type strain sporulated normally. Irradiation under BLB (Black Light Blue) light restored sporulation of the disruptants to the wild-type level (Table 1). The morphology and size of conidia of a wild type and an AGAl-targeted mutant (Igd-34) grown under BLB irradiation were compared by microscopy (Fig. 3A and B, c sections). The disruptant showed decreased conidial length and width and very few longitudinal septa were formed (Fig. 3Bc).

Development of infection structures was also examined during growth on cellulose membranes. A total of $70 \%$ of conidia for all strains germinated within $3 \mathrm{~h}$ of incubation (Fig. 4). However, germ tubes of wild-type conidia appeared from multiple points and branched frequently, whereas those of the AGAl-targeted mutants appeared only at one or both ends and

Table 1. Spore formation, AM-toxin production, and pathogenicity of wild-type strain and its transformants

\begin{tabular}{|c|c|c|c|c|}
\hline \multirow[b]{2}{*}{ Strain $^{x}$} & \multicolumn{2}{|c|}{ Conidia $\left(\times 10^{6}\right)^{\mathrm{w}}$} & \multicolumn{2}{|c|}{ Pathogenicity } \\
\hline & Normal condition & BLB irradiation & AM-toxin production ${ }^{y}$ & Lesion formation $\left(\operatorname{spots} / \mathrm{cm}^{2}\right)^{\mathrm{z}}$ \\
\hline IFO8984 & $1.18 \pm 0.22$ & $3.92 \pm 0.97$ & $0.83 \pm 0.04 \mathrm{a}$ & $16.9 \pm 1.5 \mathrm{a}$ \\
\hline $\mathrm{I}-15$ & $2.60 \pm 0.52$ & $5.70 \pm 1.69$ & $0.95 \pm 0.07 \mathrm{a}$ & $18.5 \pm 4.3 \mathrm{a}$ \\
\hline Igd-34 & - & $4.15 \pm 0.81$ & $0.99 \pm 0.02 \mathrm{a}$ & $9.6 \pm 4.3 \mathrm{~b}$ \\
\hline Igd-36 & - & $2.77 \pm 0.57$ & $1.10 \pm 0.18 \mathrm{a}$ & $9.8 \pm 2.9 \mathrm{~b}$ \\
\hline Igd-34C1 & $1.41 \pm 0.93$ & $5.34 \pm 3.05$ & nd & nd \\
\hline Igd-34C2 & $1.13 \pm 0.53$ & $4.65 \pm 0.22$ & nd & nd \\
\hline
\end{tabular}

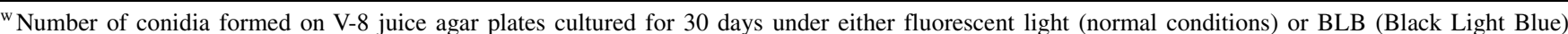
irradiation for two days after incubation for five days under normal conditions. Average and standard deviations of three experiments are shown; - indicates no conidia produced on the plates.

${ }^{x}$ Wild-type strain IFO8984, ectopic transformant I-15, AGAl-targeted mutants Igd-34 and Igd-36, and complementation strains Igd-34C1 and Igd-34C2.

${ }^{\mathrm{y}}$ For high-pressure liquid chromatography quantification of AM-toxin, the wild-type and the mutants were cultured on potato dextrose broth for 14 days at $25^{\circ} \mathrm{C}$. The toxin production is indicated by $10^{-5} \mu \mathrm{mol}$ AM-toxin I per gram of mycelial dry weight. nd $=$ not determined.

${ }^{\mathrm{z}}$ Leaves of susceptible apple cultivar Red-Gold were spray-inoculated with spore suspension $\left(10^{4} \mathrm{conidia} / \mathrm{ml}\right)$ and were incubated in a moist box at $25^{\circ} \mathrm{C}$ for $24 \mathrm{~h}$. Averages and standard deviations of three experiments are shown. Different letters in each data column indicate significant difference at $P=0.05$ as determined by Student's $t$ test. 
tended to grow in straight paths (Fig. 3A and B, a and b sections). The average number of germ tubes per conidium of wild type and disruptant were 5.13 and 1.63 , respectively. The development of infection hypha by the mutant was also slightly delayed at the early stage of spore germination (Fig. 5). However, disruption of $A G A I$ did not affect the final rate of appressorium formation (number of appressoria per germ tube) or infection-hypha formation (number of infection hyphae per appressorium) on cellulose membranes, as compared with the wild type (Fig. 5). In planta, the infection behaviors of the wild type and the disruptant on inoculated host leaves were the same as those on cellulose membranes (Fig. 3A and B, e sections), although pathogenicity was reduced. In conclusion, the actual numbers of infection structures per conidium were reduced in AGAl-targeted mutants.

The AGA1-targeted mutant Igd-34 was complemented with the AGA1-expression vector pAGA1 by cotransformation with the plasmid pII99 conferring resistance to geneticin. The AGA1-complemented strains (Igd-34C1 and Igd-34C2) showed AGAl transcript (Fig. 6) and restored the wild-type colony morphology (Fig. 6) and sporulation (Table 1).

\section{Pathogenicity and HST production of $A G A 1$ disruptant.}

Conidia of disruptant Igd-34, Igd-36, and wild-type strains were sprayed onto susceptible apple leaves, and lesion development was observed $24 \mathrm{~h}$ after inoculation. The average numbers of necrotic spots per square centimeter of leaf area induced by the wild type and the two mutants were 16.9 and 9.7, respectively (Table 1). On the other hand, there was no significant effect of $A G A 1$ disruption on lesion sizes on apple leaves. The lesion sizes $\left(\mathrm{mm}^{2}\right)$ of the wild type and the $A G A 1$ mutants Igd34 and Igd-36 were $0.10 \pm 0.10,0.08 \pm 0.09$, and $0.09 \pm 0.10$, respectively. This indicates that disruption of $A G A 1$ affects the ability of the apple pathotype to infect the host leaves.

High-pressure liquid chromatography (HPLC) analysis detected the same amount of host-specific AM-toxin I for both the wild type and the mutant at a retention time of $9.0 \mathrm{~min}$ under the conditions employed (Table 1), indicating that AGAl

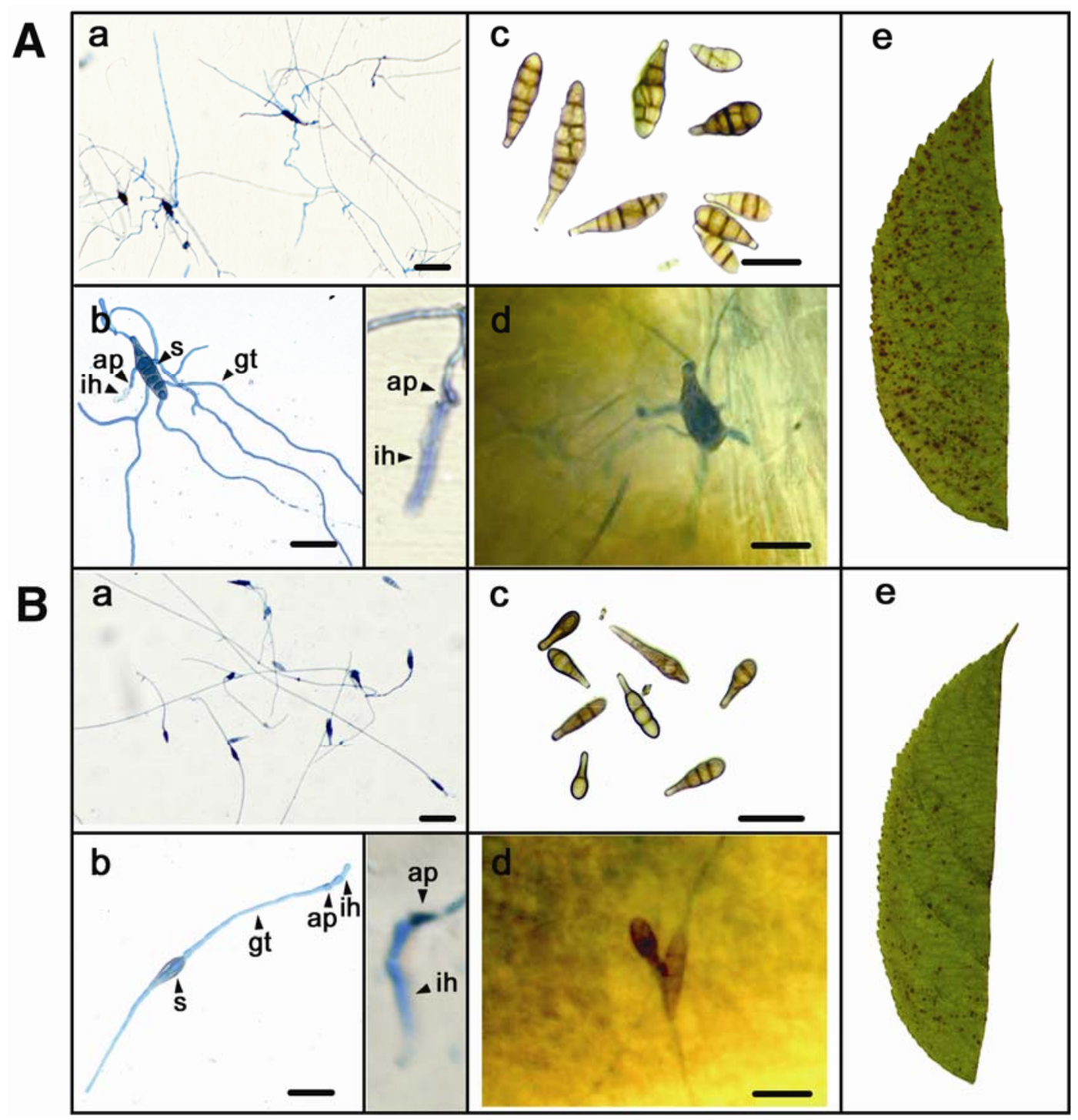

Fig. 3. Morphology of germinating spores and pathogenicity of the wild-type strain and AGA1-targeted mutants. A, Wild-type strain IFO8984 and B, AGA1targeted mutant Igd-34. a and b, Spore germination on the cellulose membrane. Spore suspensions $\left(10^{4}\right.$ conidia/ml $)$ of IFO 8984 and Igd-34 were dropped onto cellophane membranes and were incubated in a moisture chamber at $25^{\circ} \mathrm{C}$. Spore germination, germ-tube elongation, and appressorium formation were observed by microscopy after 1\% aniline blue staining. c, Spores of IFO8984 and Igd-34 formed on V-8 juice agar. The disruptant (Igd-34) showed decreased conidial length and width, and very few longitudinal septa were formed. d and e, Leaves of susceptible apple cultivar Red-Gold were sprayinoculated with spore suspension $\left(10^{4}\right.$ conidia/ml) and were incubated in a moist box at $25^{\circ} \mathrm{C}$ for $24 \mathrm{~h}$. Germinating spores on leaves were observed by microscopy after $1 \%$ aniline blue staining. ap = appressorium; $\mathrm{gt}=\mathrm{germ}$ tube; $\mathrm{ih}=$ infection hypha; and $\mathrm{s}=$ spore . 
is not involved in toxin production by this pathogen. AM-toxin production of the mutant was further confirmed by a leafnecrosis bioassay. The culture filtrates of AGAl-targeted mutants (Igd-34 and Igd-36) induced typical necrotic lesions on susceptible leaves (data not shown).

\section{Intracellular cAMP accumulation in $A G A 1$ disruptant.}

To assess the role of $A G A 1$ for G protein-regulated cAMP-dependent signaling pathway, the intracellular cAMP level in the AGA1 disruptant was measured by the cAMP EIA system. The cAMP level of disruptant Igd-34 was approximately threefold greater than that measured for wild type $24 \mathrm{~h}$ after spore germination (Table 2). For up to $48 \mathrm{~h}$ postgermination, the cAMP level of the mutant was consistently higher than that of wild type. The result indicates that $A G A 1$ negatively regulates cAMP levels, which is similar to mammalian Gai class subunits (Neer 1995) but dissimilar to most filamentous fungi studied to date, with the exception of Cryphonectria parasitica (Gao and Nuss 1996; Ivey et al. 1999; Jain et al. 2002; Lengeler et al. 2000).

\section{DISCUSSION}

We have cloned a $\mathrm{G} \alpha$ gene, $A G A 1$, from the apple pathotype of $A$. alternata to investigate possible signal transduction path-

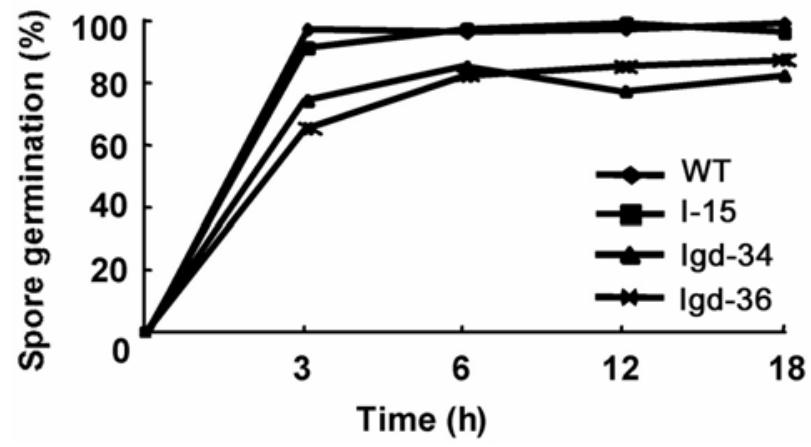

Fig. 4. Rate of spore germination of $A G A 1$-targeted mutants. Spores of wild-type strain IFO8984, ectopic transformant I-15, and AGA1-targeted mutants Igd-34 and Igd-36 were suspended in distilled water $\left(10^{5}\right.$ conidia/ml), were dropped on cellulose membranes, and were incubated at $25^{\circ} \mathrm{C}$ for indicated time intervals.

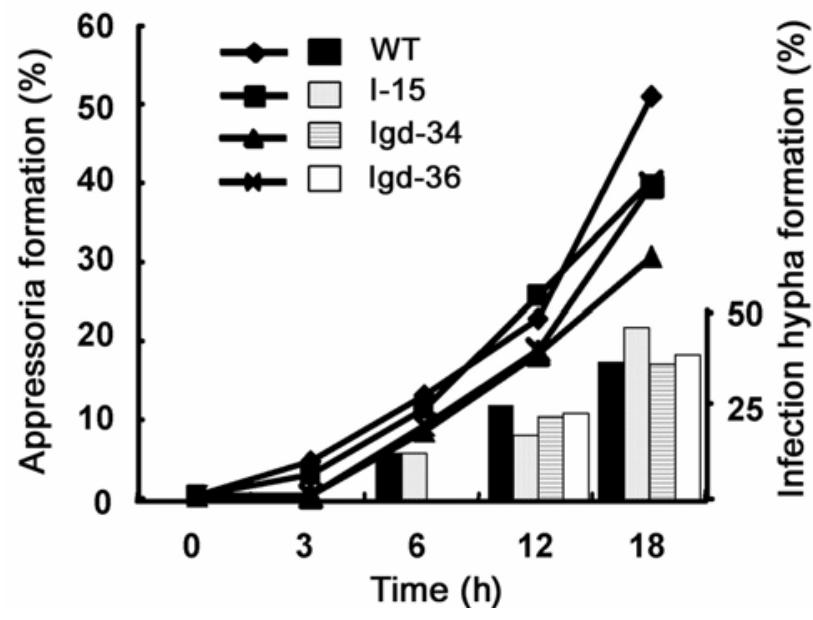

Fig. 5. Formation of appressoria and infection hypha by the wild-type strain and AGAl-targeted mutants. Spore suspensions (15 $\mu \mathrm{l}$ each, $10^{4}$ conidia/ per $\mathrm{ml}$ ) for wild type and transformants were dropped onto cellophane membranes and were incubated in a moisture chamber at $25^{\circ} \mathrm{C}$. Spore germination, germ-tube elongation, and appressorium formation were observed by microscopy after $1 \%$ aniline blue staining. ways involved in general pathogenesis that might be related to basic compatibility of toxigenic and necrotrophic pathogens. The deduced amino-acid sequence of $A G A 1$ was similar to the Gai family in mammalian systems, which inhibits adenylate cyclase (Wilkie and Yokoyama 1994). In fungi, three different classes of $\mathrm{G} \alpha$ subunits have been identified (Bölker 1998; Regenfelder et al. 1997). AGAl was placed into group I, which is characterized by an $\mathrm{N}$-terminal myristoylation site and a $\mathrm{C}$ terminus with a pertussis toxin-catalyzed ADP-ribosylation site (Pennington 1994). AGAl also contains three introns as commonly found in many fungal $\mathrm{G} \alpha$ genes.

The mammalian Gai subunit lowers intracellular cAMP levels by inhibiting adenylate cyclase activity (Chen et al. 1996). However, disruption of $\mathrm{G} \alpha$ genes in many fungi, such as gnal of $N$. crassa (Ivey et al. 1999) and fgal of F. oxysporum (Jain et al. 2002), lead to lower cAMP levels, indicating that the Gai subunits of those fungi positively control adenylate cyclase activity. In addition, application of external cAMP overcame a defect in appressorium development in $\operatorname{mag} B$ disruptants of $M$. grisea (Liu and Dean 1997). A similar stimulatory effect of Gai subunit on cAMP levels was also found for $B C G 1$ in $B$. cinerea (Gronover et al. 2001). These data indicate that the function of the Gai subunit in fungi may differ from that in their mammalian counterpart. The results we have obtained for
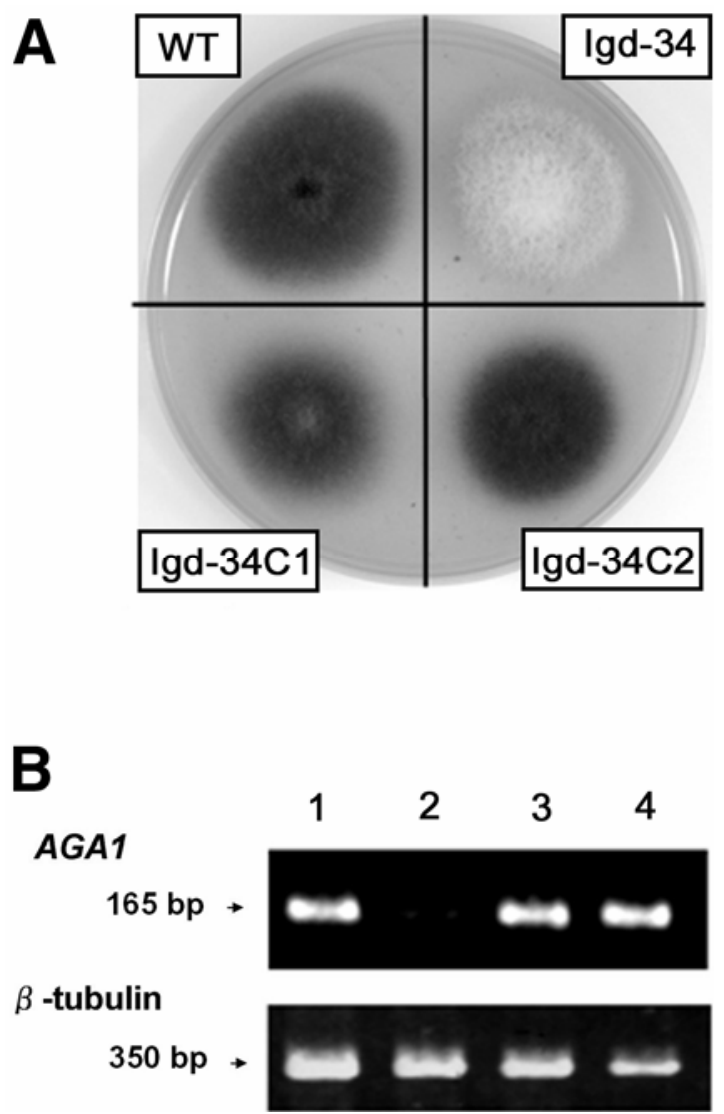

Fig. 6. Complementation of $A G A 1$ in the $A G A 1$-targeted mutant. A, Colony morphology and vegetative growth of wild-type strain IFO8984, $A G A 1$-targeted mutant Igd-34, and AGA1-complemented strains Igd-34C1 and Igd-34C2. These strains were grown on V-8 juice agar at $25^{\circ} \mathrm{C}$ for 5 days. B, Detection of $A G A 1$ transcripts in the transformants. Total RNA extracted from the wild type and transformants cultured in $50 \mathrm{ml}$ of potato dextrose broth for 2 days with shaking was used as templates for reverse transcription-polymerase chain reaction. Primers aga- $1 \mathrm{~F}$ and aga-1R amplify an internal fragment (165 bp) of $A G A 1$. Primers specific for $\beta$-tubulin were used as a positive control. 1, wild-type strain IFO8984; 2, AGA1targeted mutant Igd-34; 3 and 4, AGA1-complemented strains Igd-34C1 and Igd-34C2. 
A. alternata indicate that disruption of $A G A 1$ leads to an increase in the intracellular cAMP levels. This suggests that the Goi subunit of this pathogen may be a negative regulator of adenylate cyclase in common with mammalian systems. In Cryphonectria parasitica, the Gai (group I) gene cpgl also negatively regulates cAMP levels (Gao and Nuss 1996).

Functional analysis of fungal $\mathrm{G} \alpha$ subunits has shown that the proteins regulate multiple functions, including morphogenesis, sexual development, pigmentation, production of secondary metabolites, and virulence (Bölker 1998). In Cryphonectria parasitica, cpg-1 controls many aspects of the life cycle, including sexual and asexual reproduction, appressorium formation, and pathogenicity (Gao and Nuss 1996). The $M$. grisea $\operatorname{mag} B$ gene is involved in cAMP-dependent appressorium formation, perithecium development, and pathogenicity (Liu and Dean 1997). gpa3, one of four Ga genes of $U$. maydis is also important for mating and pathogenicity of the pathogen (Regenfielder et al. 1997). Gai class gene bcg2 from B. cinerea (Gronover et al. 2001), and Gnal from Stagonospora nodorum (Solomon et al. 2004) also affect colony morphology and ability to infect host plants. On the other hand, in Cochliobolus heterostrophus, deletion of a Gai gene, $C G A 1$, did not cause a reduction in pathogenicity, despite decreased appressorium formation and mating ability (Horwitz et al. 1999). We have shown that $A G A 1$ also controls multiple functions. In $A$. alternata disruption of $A G A 1$ results in reduced sporulation, altered conidial morphology, decrease in germ-tube formation, and reduced pathogenicity. In contrast, appressorium formation was not affected by AGAl disruption, which has been reported as a typical phenotypic change associated with $\mathrm{G} \alpha$ deletion for both Cochliobolus heterostrophus (Horwitz et al. 1999) and M. grisea (Liu and Dean 1997). In the $m a g B$ mutants of $M$. grisea, reduction in appressorium formation leads to a defect in penetration into host leaves, resulting in reduced pathogenicity (Liu and Dean 1997). However, in bcgl mutants in B. cinerea, penetration of host tissues is not disrupted but the infection process stops after formation of primary lesions (Gronover et al. 2001). A significant difference between these pathogens and A. alternata is that reduced pathogenicity in $A G A 1$ mutants corresponds to a reduction in the actual number of germ tubes formed per conidium. The final rates of appressorium formation (number of appressoria per germ tube) and infection-hypha formation (number of infection hyphae per appressorium) of the AGA1 mutant were not affected.

Spore formation of $A G A 1$ mutants decreased under normal growth conditions on potato dextrose agar (PDA) media but was restored by irradiation under BLB light. Spores of the mutant had decreased conidial width and only transversal septa were formed. In addition, germ tubes of the mutant were formed only at each end of conidium and grew in straight

Table 2. Quantification of intracellular cyclic AMP of the wild-type strain and the $A G A 1$-targeted mutant

\begin{tabular}{|c|c|c|}
\hline \multirow[b]{2}{*}{ Strain $^{y}$} & \multicolumn{2}{|c|}{ cAMP concentration (pmol/mg of protein $)^{\mathrm{z}}$} \\
\hline & $24 \mathrm{~h}$ & $48 \mathrm{~h}$ \\
\hline IFO8984 & $3.20 \pm 1.87 \mathrm{a}$ & a \\
\hline $\operatorname{lgd}-34$ & $9.10 \pm 3.50 \mathrm{~b}$ & $2.40 \mathrm{~b}$ \\
\hline \multicolumn{3}{|c|}{$\begin{array}{l}{ }^{\mathrm{y}} \text { Wild-type strain IFO } 8984 \text { and } A G A l \text {-targeted mutant Igd- } 34 \text {. } \\
\mathrm{z} \text { Spore suspensions }\left(10^{5} \text { conidia/ml }\right) \text { of the wild-type strain IFO } 8984 \text { and } \\
\text { the } A G A 1 \text {-targeted mutant Igd- } 34 \text { were incubated for } 24 \text { and } 48 \mathrm{~h} \text { at } \\
26^{\circ} \mathrm{C} \text { on the cellulose membrane. Germinating spores were collected and } \\
\text { intracellular cAMP was extracted and detected with the cAMP enzyme } \\
\text { immunoassay system. Averages and standard deviations of three } \\
\text { experiments are shown. Different letters in each data column indicate } \\
\text { significant difference at } P=0.05 \text { as determined by Student's } t \text { test. }\end{array}$} \\
\hline
\end{tabular}

paths. In contrast, spores of the wild-type strain have longitudinal septa and germ tubes formed from multiple points around the conidia and branched frequently. The described features in the morphogenic changes of the A. alternata mutant have not been previously reported in other fungal $\mathrm{G} \alpha$ mutants.

The pathological significance of appressoria was discussed through the results of $\mathrm{G} \alpha$ gene deletion in Cochliobolus heterostrophus (Horwitz et al. 1999). The magB mutants of $M$. grisea have reduced virulence corresponding to a reduction in appressorium formation, whereas the cgal mutant of Cochliobolus heterostrophus has no detectable changes in virulence. The author's interpretation was that infection structures are not critical for infection in fungi producing small nonmelanized appressoria, such as Cochliobolus heterostrophus, whereas it would be important in fungi with large melanized appressoria, such as M. grisea and Colletotrichum lagenarium (Horwitz et al. 1999). The authors also mentioned possible roles of appressoria in A. alternata that produce small appressoria similar to Cochliobolus heterostrophus; appressoria might be optional for infection by the pathogen (Horwitz et al. 1999). The $\triangle A G A l$ mutant of A. alternata still produces normal appressoria with infection hypha in this study, and hence, the role of the infection structure in the pathogen is still unclear.

Previous studies on $\mathrm{G}$ proteins in Aspergillus spp. revealed that production of toxic secondary metabolites in these fungi are controlled by G $\alpha$ genes (Yu and Keller 2005). Biosynthesis of the carcinogenic mycotoxins sterigmatocystin and aflatoxin is negatively regulated by $\mathrm{G} \alpha$ subunit FadA (Hicks et al. 1997). In contrast, the dominant activating fadA allele $\mathrm{fadA}^{\mathrm{G} 42 \mathrm{R}}$ increases penicillin production by $A$. nidulans and also stimulates mycotoxin trichothecene production by $F$. sporotrichioides (Tag et al. 2000). The results indicate that $\mathrm{G} \alpha$ proteins in fungi have diverse effects on the production of different toxic secondary metabolites. The authors also pointed out that $\mathrm{G}$ proteintargeting strategies for controlling fungal pathogenicity (Kwon-Chung 1998) could lead to undesirable increases in the production of unwanted fungal secondary metabolites (Tag et al. 2000). We examined the effect of G $\alpha$ proteins on the biosynthesis of HST, which have critical roles in fungal patho-

Table 3. Oligonucleotide primers used in this study

\begin{tabular}{|c|c|c|}
\hline Primer & Sequence $\left(5^{\prime} \rightarrow 3^{\prime}\right)^{\mathrm{z}}$ & Amplicon \\
\hline aga-1F & GTGGATACACTGCTTCGAGA & \\
\hline aga-1R & TGATGGATGTCTTGACGAAC & $165 \mathrm{bp}$ \\
\hline caga1-F & $\begin{array}{l}\text { GGGGTACCCCATCATGGGTTGCGGAA } \\
\text { TGA }\end{array}$ & \\
\hline caga1-R & $\begin{array}{l}\text { GGGGTACCCCTAGGACATGAGGCATG } \\
\text { CAAC }\end{array}$ & $1,290 \mathrm{bp}$ \\
\hline P1f & CCGGATCGCTTCCAGTCCGTCTCAC & \\
\hline P1r & $\begin{array}{l}\text { CCCAAGCTTGGGAGCACGTCTTGGTC } \\
\text { GTTG }\end{array}$ & $827 \mathrm{bp}$ \\
\hline $\mathrm{P} 2 \mathrm{f}$ & $\begin{array}{l}\text { GCTCTAGAGCTTCACCTGCGCCACAG } \\
\text { ACAC }\end{array}$ & \\
\hline $\mathrm{P} 2 \mathrm{r}$ & TTGGGAGCCGCCGTAAACATACGCT & $497 \mathrm{bp}$ \\
\hline Pn71f & $\begin{array}{l}\text { CCCAAGCTTGGGAGCTATGACCATGA } \\
\text { TTAC }\end{array}$ & \\
\hline Pn71r & $\begin{array}{l}\text { GCTCTAGAGCGGTGTTACGGAGCATT } \\
\text { CACT }\end{array}$ & $3,86 \mathrm{bp}$ \\
\hline Pn71f2 & GGGGTACCCCAGTAGATGCCGACCG & \\
\hline Pn71r2 & GGGGTACCCCGGTGATGCTGCTCAAG & 5,736 bp \\
\hline$\beta$-tub1 & $\begin{array}{l}\text { TCCGTCGTGCCTTCCCCCAAGGTCTCC } \\
\text { GAC }\end{array}$ & \\
\hline$\beta$-tub2 & $\begin{array}{l}\text { GGAGCGAATCCGACCATGAAGAAGTG } \\
\text { GAGA }\end{array}$ & $350 \mathrm{bp}$ \\
\hline
\end{tabular}

${ }^{\mathrm{z}}$ Recognition sequences for restriction enzymes are underlined. 
genesis. Host-specific AM-toxin production by $A G A 1$ mutants of the apple pathotype of A. alternata was unaltered compared with that of the wild-type strain, indicating that production of this host-specific toxin in A. alternata is unlikely to be related to AGA1-mediated regulation cascades. This also suggests that targeting $\mathrm{G}$ protein-signaling pathways may not provide effective strategies for controlling toxin production and pathogenicity of A. alternata pathogens.

\section{MATERIALS AND METHODS}

Plant material, fungal strains, and culture conditions.

Apple (Malus domestica Borkh.) leaves were obtained from greenhouse-grown apple trees of the highly susceptible cultivar Red-Gold. Isolates of A. alternata apple pathotype (strains M-71 and IFO8984) were maintained on PDA (Difco, Detroit) slopes or as $15 \%$ glycerol spore suspensions at $-80^{\circ} \mathrm{C}$.

\section{PCR cloning of the $A G A 1$ gene.}

A set of degenerate primers (agaF, 5'-GAG CRT GGA THC AYT GYT-3' and agaR, 5'-GCR TCY TTY TTR TTN ARR AA-3') was designed from CGAl of Cochliobolus heterostrophus (Horwitz et al 1999). To facilitate cloning, XbaI sites were incorporated at the $5^{\prime}$ ends. PCR was performed on genomic DNA of A. alternata M-71 using the following conditions: $20 \mathrm{ng}$ of genomic DNA was added to a $20-\mu \mathrm{l}$ reaction containing dNTPs at a final concentration of $250 \mu \mathrm{M}$ (Takara, Ohtsu, Japan), 1× PCR buffer (Takara), primers agaF and agaR at a final concentration of $1 \mu \mathrm{M}$, and 1.0 $\mathrm{U}$ of Taq DNA polymerase (Takara). PCR was performed in a GeneAmp PCR system 9600 (Applied Biosystems, Foster City, CA, U.S.A.) with an initial step of $5 \mathrm{~min}$ at $95^{\circ} \mathrm{C}$, followed by 30 cycles of $15 \mathrm{~s}$ at $95^{\circ} \mathrm{C}, 15 \mathrm{~s}$ at $42^{\circ} \mathrm{C}, 30 \mathrm{~s}$ at $72^{\circ} \mathrm{C}$, and a final step of 5 min at $72^{\circ} \mathrm{C}$. PCR products were cloned into pBluescript II $\mathrm{KS}^{+}$and then were transformed into Escherichia coli $\mathrm{DH} 5 \alpha$. The nucleotide sequence of representative clones was determined by the DNA sequencing kit (Applied Biosystems) and an automated sequencing system (ABI Prism 310, Applied Biosystems). DNA was sequenced in both directions and sequence construction was performed with Sequencer (Gene Codes, Ann Arbor, MI, U.S.A.) and Genetyx-Mac (Software Development, Tokyo).

\section{Library screening.}

A genomic Lambda Zap (Stratagene, La Jolla, CA, U.S.A.) library of A. alternata (strain M-71) was constructed as described previously (Johnson et al. 2000). An AGAl fragment was simultaneously amplified and labeled with a digoxigenin (DIG) PCR labeling kit (Roche Diagnostics, Tokyo) with primer pairs aga-1F and aga-1R (Table 3) corresponding to the original degenerate PCR product. PCR cycling conditions were as described above, except that the annealing temperature was $65^{\circ} \mathrm{C}$ and the extension temperature $72^{\circ} \mathrm{C}$. Membranes were hybridized with DIG-labeled probes and were washed according to the manufacturer's instructions (Roche Diagnostics). Hybridizing plaques were detected with a colorimetric reaction according to the manufacturer's instructions (Roche Diagnostics). Positive plaques were selected and subjected to further rounds of screening until pure. Individual positive plaques were converted to $\mathrm{pBK}-\mathrm{CMV}$ phagemids by in vivo excision according to the manufacturer's instructions and were maintained on Luria-Bertani agar supplemented with $50 \mu \mathrm{g}$ of kanamycin per milliliter. Phagemid DNA was isolated from overnight cultures of host strain XLOR with the Plasmid mini kit (Qiagen, Tokyo) and was sequenced with T3 and T7 primers that flank the insert. Primer walking was used to obtain the full sequence of the overlapping clones. Clone pGA21 was chosen for further analysis and vector construction.

\section{Vector construction.}

The disruption vector was constructed by PCR using six primers indicated in Table 3. A 0.9-kb fragment with an artificial $X b a$ I site at the $3^{\prime}$ end and a $0.5-\mathrm{kb}$ fragment with an artificial HindIII site at the $5^{\prime}$ end were amplified from pGa21 (containing AGA1), with the primer pairs P1f and P1r and P2f and P2r, respectively (Fig. 1A). PCR products were ligated with the $h p h$ (hygromycin B-resistant gene) cassette amplified from the plasmid pAN7-1 (Punt et al. 1987), with primer pairs Pn71f and Pn71r containing artificial HindIII and XbaI sites at the ends. The ligated fragment was finally amplified with primers P1f and P2r to obtain the disruption vector fAGa-1 (Fig. 1A). The PCR product (fAGa-1) was used for transformation.

The complementation vector was constructed as follows. The entire region of plasmid pAN7-1 (Punt et al. 1987) except the $h p h$ sequence was amplified from the plasmid by PCR, using the primer pair Pn71f2 and Pn71r2, which contain a KpnI site at both ends (Table 3). The PCR product was digested with $K p n I$. The coding region from the initiation codon to the termination codon of $A G A l$ was amplified from genomc DNAs of IFO8984, using the primer pair caga1-F and caga1-R, containing a KpnI site at both ends (Table 3 ). The amplified DNA was digested with $K p n I$ and was ligated with the PCR product derived from pAN7-1, as mentioned above. The direction of $A G A 1$ was confirmed by sequencing, and the plasmid with the right direction of $A G A 1$ was designated as pAGA1. AGAl is expressed under the control of the gpd promoter from Aspergillus nidulans in pAGA1.

\section{Transformation.}

Protoplasts were prepared from the wild type of A. alternata apple pathotype as described previously (Akamatsu et al. 1997), except that $10 \mathrm{mg}$ of lysing enzyme per milliliter (Sigma-Aldrich, St. Louis) and $10 \mathrm{mg}$ of kitalase per milliliter (Wako Pure Chemicals, Osaka, Japan) replaced the enzymes originally used. Protoplasts $\left(1 \times 10^{7}, 80 \mu \mathrm{l}\right)$ were transformed with pAGa-1 by methods described previously (Akamatsu et al. 1997). Integration of the $h p h$ cassette by a double-crossover homologous recombination event at the $A G A 1$ locus was determined by PCR. Primers used to detect the junctions between the construct and genomic sequences are shown in Table 3 and Figure 1A. PCR conditions were an initial step of $5 \mathrm{~min}$ at $95^{\circ} \mathrm{C}$ followed by 30 cycles of $20 \mathrm{~s}$ at $95^{\circ} \mathrm{C}, 30 \mathrm{~s}$ at $60^{\circ} \mathrm{C}, 4$ min at $72^{\circ} \mathrm{C}$, and a final step of $5 \mathrm{~min}$ at $72^{\circ} \mathrm{C}$. Putative disruptants yielding the expected diagnostic amplification fragments (Fig. 1B) were purified by single-spore isolation.

\section{Genetic complementation of $A G A 1$-targeted mutant.}

The AGAl-targeted mutant Idg-34 was complemented with the $A G A 1$-expression vector pAGA1 by cotransformation with the plasmid pII99 (Namiki et al. 2001) conferring resistance to geneticin (Inoue et al. 2002). Geneticin-resistant transformants were grown on a PDA containing hygromycin and geneticin at $50 \mu \mathrm{g} / \mathrm{ml}$ and $100 \mu \mathrm{g} / \mathrm{ml}$, respectively. Expression of $A G A l$ in the transformants (Igd-34C1 and Igd-34C2) was determined by RT-PCR as described below.

\section{Phenotypic characterization of transformants.}

For the analysis of growth on solid media, mycelial disks (10 $\mathrm{mm}$ in diameter) were placed on PDA and V8A plates. The plates were incubated at $25^{\circ} \mathrm{C}$ for measurement of colony diameters. Conidia formed on V8A under BLB or fluorescent 
light irradiation were harvested, and the number of spores were counted with a hemacytometer.

For the observation of infection behavior and infectionstructure formation, $15 \mu \mathrm{l}$ of spore suspension $\left(10^{4}\right.$ conidia $\left./ \mathrm{ml}\right)$ of wild type and transformants were dropped onto cellophane membranes (Wako Pure Chemicals) and were incubated in a moisture chamber at $25^{\circ} \mathrm{C}$. Spore germination, germ-tube elongation, and appressorium formation were observed by microscopy after $1 \%$ aniline blue staining.

\section{Pathogenicity and AM-toxin production.}

Spores of wild type and transformants were collected from 7-day-old cultures on V8A under BLB light for three days. Spores were washed three times in sterile water, and suspensions $\left(1 \times 10^{5}\right.$ conidia $\left./ \mathrm{ml}\right)$ were sprayed onto the underside of detached leaves of susceptible cultivar Red-Gold with a glass atomizer and were incubated at $26^{\circ} \mathrm{C}$ for $48 \mathrm{~h}$ in the dark. To determine host-specific AM-toxin production, the wild type and transformants were grown statically at $26^{\circ} \mathrm{C}$ in $50 \mathrm{ml}$ of Czapek Dox medium (Oxoid, Hampshire, U.K.) supplemented with $0.5 \%$ yeast extract (Difco) for 14 days. AM-toxin production in cultures was determined by HPLC analysis as previously described (Johnson et al. 2000). For a leaf-necrosis bioassay, the culture filtrates of those strains were collected and $20 \mu \mathrm{l}$ was placed onto the underside of a young leaf of highly susceptible cultivar Red-Gold that had been slightly wounded by scratching the epidermis. Leaves were incubated at $26^{\circ} \mathrm{C}$ overnight in the dark and were assessed for necrosis after $24 \mathrm{~h}$.

\section{RT-PCR.}

The wild type and transformants were cultured in $50 \mathrm{ml}$ of potato dextrose broth for 2 days with shaking (100 rpm). Fungal mycelia were collected and frozen at $-80^{\circ} \mathrm{C}$. Frozen mycelium (100 mg of fresh weight) was used to prepare total RNA by the RNeasy plant mini kit (Qiagen), using the manufacturer's instructions. Total RNA $(10 \mu \mathrm{g})$ was treated with DNaseI (Nippongene, Toyama, Japan) to remove traces of contaminating DNA, and $1 \mu \mathrm{g}$ was then reverse transcribed into cDNA, using the RNA PCR kit version 2.1 (Takara) according to the manufacture's conditions. Primers aga-1F and aga-1R were used for $A G A 1$ and $\beta$-tub1 and $\beta$-tub2 for $\beta$ tubulin (Table 3 ).

\section{Quantification of cyclic AMP.}

Intracellular cAMP was extracted and detected with the cAMP enzyme immunoassay (EIA) system (Amersham Pharmacia Biotech, Piscataway, NJ, U.S.A.), according to the manufacturer's instructions. Spore suspensions $\left(10^{5}\right.$ spores $)$ of the wild type and transformants were dropped onto cellophane membrane (Wako Pure Chemicals) and were incubated for 24 and $48 \mathrm{~h}$ at $26^{\circ} \mathrm{C}$. Germinating spores were collected and immediately frozen in liquid nitrogen and then ground to a powder. Samples were suspended with ice-cold $6 \%$ (wt/vol) tricarboxylic acid (TCA) and were centrifuged. The supernatant was extracted with water-saturated diethyl ester to remove TCA. Extracted sample were lyophilized and, finally, were resuspended with $200 \mu$ l of assay buffer (Amersham Pharmacia Biotech). Protein concentration was quantified by the Bio-Rad protein assay (Bio-Rad, Hercules, CA, U.S.A.) .

\section{ACKNOWLEDGMENTS}

We are grateful to R. D. Johnson for valuable suggestions. We also thank H. Matsui and H. Akamatsu for technical assistance, R. P. Oliver for providing pAN7-1, and T. Tsuge for providing pII99. This work was supported by a grant-in-aid for scientific research from the Japanese Society for Promotion of Sciences.

\section{LITERATURE CITED}

Akamatsu, H., Itoh, Y., Kodama, M., Otani, H., and Kohmoto, K. 1997. AAL-toxin-deficient mutants of Alternaria alternata tomato pathotype by restriction enzyme-mediated integration. Phytopathology 87:967-972.

Altschul, S. F., Madden, T. L., Schaffer, A. A., Zhang, J., Zhang, Z., Miller, W. and Lipman, D. J. 1997. Gapped BLAST and PSI-BLAST: A new generation of protein database search programs. Nucleic Acids Res. 25:3389-3402.

Bölker, M. 1998. Sex and crime: Heterotrimeric G protein in fungal mating and pathogenesis. Fungal Genet. Biol. 25:143-156.

Buss J. E., Mumby S. M., Casey, P. J., Gilman, A. G., and Sefton, B. M. 1987. Myristoylated $\alpha$ subunits of guanine nucleotide-binding regulatory proteins. Proc. Natl. Acad. Sci. U.S.A. 84:7493-7497

Chen., Y., Liu, J., and Yu, L. 1996. Functional coupling of a $\mu$ opioid receptor to $\mathrm{G}$ proteins and adenylyl cyclase: Modulation by chronic morphine treatment. Addict. Biol. 1:49-59.

Gao, S., and Nuss, D. L. 1996. Distinct roles for two G protein alpha subunits in fungal virulence, morphology and reproduction revealed by targeted gene disruption. Proc. Natl. Acad. Sci. U.S.A. 93:14122-14127.

Gronover, C. S., Kasulke, D., Tudzynski, P., and Tudzynski, B. 2001. The role of $G$ protein alpha subunits in the infection process of the gray mold fungus Botrytis cinerea. Mol. Plant-Microbe Interact. 14:12931302.

Hatta, R., Ito, K., Hosaki, Y., Tanaka, T., Tanaka, A., Yamamoto, M., Akimitsu, K., and Tsuge, T. 2002. A conditionally dispensable chromosome controls host-specific pathogenicity in the fungal plant pathogen Alternaria alternata. Genetics 161:59-70.

Hicks, J. K., Yu, J.-H., Keller, N. P., and Adams, T. H. 1997. Aspergillus sporulation and mycotoxin production both require inactivation of the FadA G $\alpha$ protein-dependent signaling pathway. EMBO (Eur. Mol. Biol. Organ.) J. 16:4916-4923.

Horwitz, B. A., Sharon, A., Lu, S.-W., Ritter, V., Sandrock, T. M., Yoder, O. C., and Turgeon, B. G. 1999. A G protein alpha subunit from Cochliobolus heterostrphus involved in mating and appressorium formation. Fungal Genet. Biol. 26:19-32.

Idnurm, A., and Howlett, B. J. 2001. Pathogenicity genes of phytopathogenic fungi. Mol. Plant Pathol. 2:241-255.

Inoue, I., Namiki, F. and Tsuge, T. 2002. Plant colonization by the vascular wilt fungus Fusarium oxysporum requires $F O W 1$, a gene encoding a mitochondrial protein. Plant Cell. 14:1869-1883.

Isshiki, A., Akimitsu, K., Yamamoto, M. and Yamamoto, H. 2001. Endopolygalacturonase is essential for citrus black rot caused by Alternaria citri but not brown spot caused by Alternaria alternata. Mol. PlantMicrobe Interact. 14:794-757.

Ivey, F. D., Yang, Q., and Borkovich, K. A. 1999. Positive regulation of adenyl cyclase activity by a Gai homolog in Neurospora crassa. Fungal. Genet. Biol. 26:48-61.

Jain, S., Akiyama, K., Mae, K., Ohguchi, T., and Takata, R. 2002. Targeted disruption of a $\mathrm{G}$ protein $\alpha$ subunit gene results in reduced pathogenicity in Fusarium oxysporum. Curr. Genet. 41:407-413.

Johnson, R. D., Johnson, L., Itoh, Y., Kodama, M., Otani, H., and Kohmoto, K.. 2000. Cloning and characterization of a cyclic peptide synthetase gene from Alternaria alternata apple pathotype whose product is involved in AM-toxin synthesis and pathogenicity. Mol. Plant-Microbe Interact. 13:742-753.

Kohmoto, K., and Otani, H. 1991. Host recognition by toxigenic plant pathogens. Experimentia 47:755-764.

Kohmoto, K., Taniguchi, T., and Nishimura, S. 1974. Correlation between the susceptibility of apple cultivars to Alternaria mali and their sensitivity to AM-toxin I. Ann. Phytopathol. Soc. Jpn. 43:65-66.

Kwon-Chung, K. J., Goldman, W. E., Klein, B., and Szaniszlo, P. J. 1998. Fate of transforming DNA in pathogenic fungi. Med. Mycol. 36:38-44.

Lengeler, K. B., Davidson, R. C., D'Souza, C., Harashima, T., Shen, W. C., Wang, P., Pan, X. W., Waugh, M., and Heitman, J. 2000. Signal transduction cascades regulating fungal development and virulence. Microbiol. Mol. Biol. Rev. 64:746-785.

Liu, S., and Dean, R. A. 1997. G protein alpha subunit genes control growth, development, and pathogenicity of Magnaporthe grisea. Mol. Plant-Microbe Interact. 10:1075-1086.

Markham, J. E. and Hille, J. 2001. Host-selective toxins as agents of cell death in plant-fungus interactions. Mol. Plant Pathol. 2: 229-239.

Namiki, F., Matsunaga, M., Okuda, M., Inoue, I., Nishi, K., Fujita, Y., and Tsuge, T. 2001. Mutation of an arginine biosynthesis gene causes reduced pathogenicity in Fusarium oxysporum f. sp. melonis. Mol. PlantMicrobe Interact. 14:580-584.

Neer, E. J., 1995. Heterotrimeric G proteins: Organisers of transmembrane signals. Cell. 80:249-257.

Nishimura, S., and Kohmoto, K. 1983. Host-specific toxins and chemical structures from Alternaria species. Annu. Rev. Phytopathol. 21:87-116. 
Okuno, T., Ishita, Y., Sawai, K., and Matsumoto, T. 1974. Characterization of alternariolide, a host-specific toxin produced by Alternaria mali Roberts. Chem. Lett. 1974:635-638.

Otani, H., Kohmoto, K., and Kodama, M. 1995. Alternaria toxins and their effects on host plants. Can. J. Bot. 73:S453-S458.

Pennington, S. R. 1994. GTP-binding proteins I: Heterotrimeric G proteins. Protein Profiles 1:169-233.

Punt, P. J., Oliver, R. P., Dingemanse, M. A., Pouwels, P. H. and van den Hondel, C. A. M. J. J. 1987. Transformation of Aspergillus based on the hygromycin B resistance marker from Escherichia coli. Gene 56:117124.

Regenfelder, E., Spellig, T., Hartmann, A., Lauenstein, S., Bölker, M., and Kahmann, R. 1997. G proteins in Ustilago maydis: Transmission of multiple signals? EMBO (Eur. Mol. Biol. Organ.) J. 16:1934-1942.

Sawamura, K. 1966. Studies on spotted disease of apples. 6. On the hostspecific toxin of Alternaria mali Roberts. Bull. Hortic. Res. Stn. Japan, Ser. C. 4:43-59.

Simon, M. I., Strathmann, M. P., and Gautam, N., 1991. Diversity of G proteins in signal transduction. Science 252:802-808.

Solomon, P. S., Tan, K.-C., Sanchez, P., Cooper, R. M., and Oliver, R. P., 2004. The disruption of a $\mathrm{G} \alpha$ subunit sheds new light on the pathogenicity of Stagonospora nodorum on wheat. Mol. Plant-Microbe Interact. 17:456-466.

Tag, A., Hicks, J., Garifullina, G., Ake, C., Jr., Phillips, T. D., Beremand, M., and Keller, N. 2000. G-protein signaling mediates differential production of toxic secondary metabolites. Mol. Microbiol. 38:658-665.

Tanaka, A., Shiotani, H., Yamamoto, M., and Tsuge, T. 1999. Insertional mutagenesis and cloning of the genes required for biosynthesis of the host-specific AK-toxin in the Japanese pear pathotype of Alternaria al- ternata. Mol. Plant-Microbe Interact. 12:691-702.

Thomma, B. P. H. J. 2003. Alternaria spp.: From general saprophyte to specific parasite. Mol. Plant Pathol. 4:225-236.

Truesdell, G. M., Yang, Z., and Dickman, M. B. 2000. A G $\alpha$ subunit gene from the phytopathogenic fungus Colletotrichum trifolii is required for conidial germination. Physiol. Mol. Plant Pathol. 56:131-140.

Turner, G. E., and Borkovich, K. A. 1993. Identification of a G protein $\alpha$ subunit from Neurospora crassa that is a member of the Gi family. J. Biol. Chem. 268:14805-14811.

Walton, J. D. 1996. Host-selective toxins: Agents of compatibility. Plant Cell 8:1723-1733.

West, R. E. J., Moss, J., Vaughan, M., Liu, T., and Liu, T. Y. 1985. Pertussis toxin-catalyzed ADP-ribosylation of transducin. Cysteine 347 is the ADP-ribose acceptor site. J. Biol. Chem. 260:14428-14430.

Wilkie, T. M., and Yokoyama, S. 1994. Evolution of the G protein alpha subunit multigene family. Soc. Gen. Physiol. Ser. 49:249-70.

Wolpert, T. J., Dunkle, L. D. and Ciuffetti, L. M. 2002. Host-selective toxins and avirulence determinants: What's in a name? Annu. Rev. Phytopathol. 40:251-85.

Yao, C. L., and Koller, W. 1995. Diversity of cutinases from plant-pathogenic fungi-Different cutinases are expressed during saprophytic and pathogenic stages of Alternaria brassicicola. Mol. Plant-Microbe Interact. 8:122-130.

Yu, J.-H., and Keller N. 2005. Regulation of secondary metabolism in filamentous fungi. Annu. Rev. Phytopathol. 43:437-458.

Yu, J.-H., Wieser, J., and Adams, T. H. 1996. The Aspergillus FLBA RGS domain protein antagonizes G-protein signaling to block proliferation and allow development. EMBO (Eur. Mol. Biol. Organ.) J. 15:51845190 . 